\title{
Research on the embankment compaction characteristics of Metamorphic Phyllite
}

\author{
Bi Ran ${ }^{1,}$, Liu Baojian ${ }^{1, b}$ and Tang Xiao ${ }^{2, c}$ \\ ${ }^{1}$ School of road and railway engineering, Chang'an University, Shaanxi 710064, China; \\ ${ }^{2}$ CCCC First Highway Consultants Co. Ltd, Shaanxi 710075, China. \\ aranbiwork@126.com, bys02@gl.chd.edu.cn, ${ }^{\mathrm{c}} 361571622 @ q q . c o m$
}

\begin{abstract}
Keywords: metamorphic phyllite, embankment compaction, reliable pressure level, compaction test,
\end{abstract} california bearing ratio (CBR) test.

\begin{abstract}
Metamorphci phyllite is fragile, the gradation show large variation. Different pressure levels are selected at first to make sure the stable gradation. The test results show that $600 \mathrm{kPa}$ pressure level meets the requirement and metamorphic under this level is choose for further compaction analysis. Compaction tests are carried out based on different pressure levels, in order to make the comparison of grain breakage at different pressure level and eliminate the low pressure level grain breakage influence. Interior california bearing ratio (CBR) tests are carried based on the reliable pressure level, too. The results show that the maximum dry density and optimum mositure content are changing together with different pressure levels, for our project, the reliable maximum dry density is $2.46 \mathrm{~g} / \mathrm{cm}^{3}$ and correspond to optimum mositure content is $5.4 \%$ with the sample of pressure level of $600 \mathrm{kPa}$. CBR tests based on the reliable pressure level meets the requiement of embankment filling standard, which gurantees the safety of the project using metamorphic phyllite in the view of embankment compaction construction.
\end{abstract}

\section{General Introduction}

In the southwest of China, Metamorphic rock is widely spread due to the geological distribution. According to the government road net improvement plan, the metamorphic phyllite as one kind of the soft rocks, it is high weathered due to the environmental factor and shows low strength features. When taken the economy and environment into consideration, the soft rock treats as the project abandoned material is selected as the embankment filler material in many construction fields [1-5]. For example, the sedimentary rock is applied to the embankment filling by Japen in Dongming highway road project in the 1960s. Lots of researchers study the soft rock application. Bo Gonglin investigates the usage of abandoned material in the design and construction work of embankment filling [6]; Liu jian analyzes the characteristics of the original state of soft rock while encounters water and finds out the sericite schist is sensitive to the water influence[7]; Liu Xinxi carries out seriously weathered soft rock compaction test analysis[8]; Zheng Mingxin focus his attention on phyllite slate and argillaceous siltstone along Wuguang passenger dedicated railway line and works out its physical and engineering mechanicals[9].

The metamorphic phyllite gathered from Sichuan province is analyzed. Due to the imperfect performance of the soft rock in the embankment compaction according to the previous study by the researchers, detail study of the metamorphic phyllite embankment compaction characteristics are carried on.

\section{Tests Analysis}

Grain Size Distribution. The metamorphic phyllite gradation distribution is analyzed under the pressure of different levels, which are $100 \mathrm{kPa}, 200 \mathrm{kPa}, 300 \mathrm{kPa}, 400 \mathrm{kPa}, 500 \mathrm{kPa}, 600 \mathrm{kPa}, 700 \mathrm{kPa}$, $800 \mathrm{kPa}$. This is due to the consideration of metamorphic phyllite's fragile property, which influences the grain size distribution greatly. Therefore, it is important to first study the relatively stable 
gradation feature, which guarantees the accuracy of the embankment compaction analysis. The test result is shown in Fig. 1.

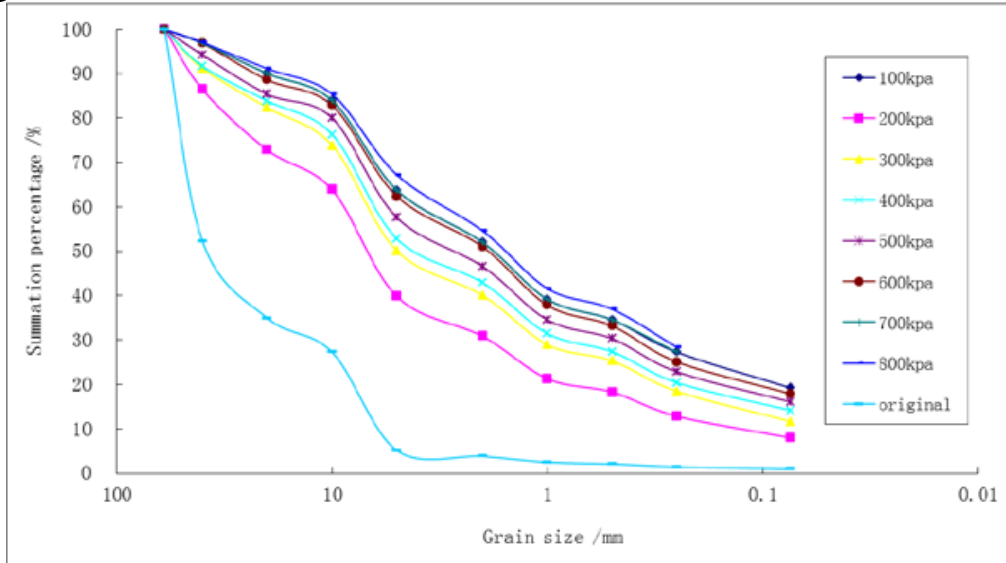

Figure 1. Gradation curve under different levels of pressure

Based on the tests results, fully grain size distribution features of metamorphic phyllite are gathered. It follows the pattern that along with the increasing of the pressure level the grain size turns smaller, but the changing speed is not the same. According to the data, under the pressure level of 100 $\mathrm{kPa}$ to $300 \mathrm{kPa}$, the rate shows fast. This is due to the vulnerable fragile characteristics of phyllite. However at the pressure of $600 \mathrm{kPa}$, the gradation turns stable, even with the increasing of the pressure, the gradation does not change too much. Therefore, pressure level of $600 \mathrm{kPa}$ could serve as an indicator pressure level for further embankment compaction analysis.

Compaction Test. Taken the pressure level of $600 \mathrm{kPa}$ into consideration, the compaction test of the metamorphic phyllite analysis is worked out. Based on this pressure level, the results are shown in Fig. 2 and Table 1, the metamorphic phyllite under the pressure of $600 \mathrm{kPa}$ is treated as the reliable state for our compaction test. In order to fully express the truly maximum dry density and optimum moisture content, the samples are selected by different pressure level, which the pressure under 600 $\mathrm{kPa}$ are counted in as comparison.

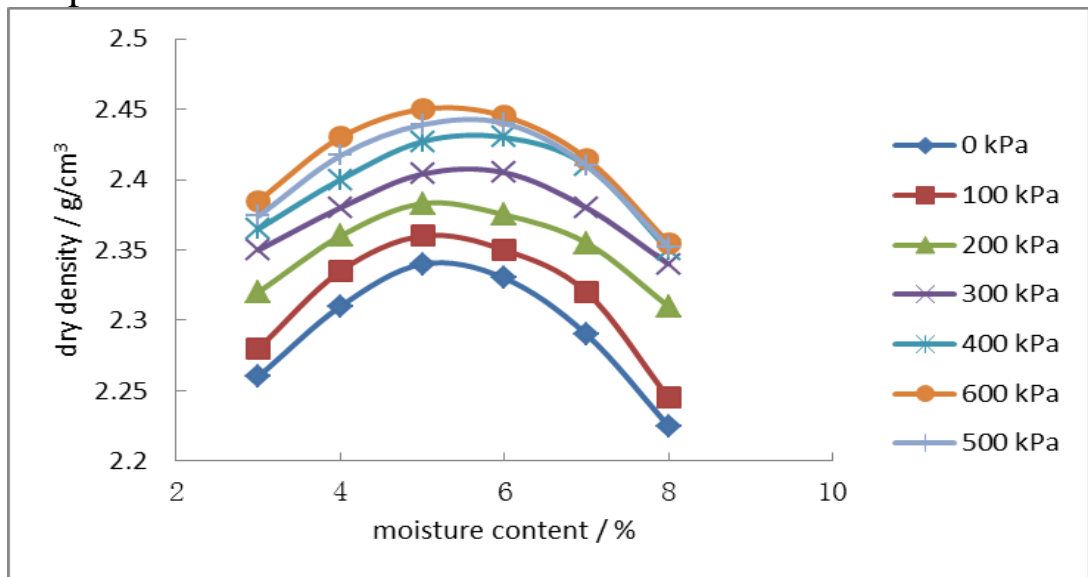

Figure 2 Relationship of moisture content and dry density under different pressure levels

From the results, density under the pressure level of $600 \mathrm{kPa}$ is the highest among these seven curves and according to the fragile property of metamorphic phyllite, the guiding data is selected from this pressure. Under the pressure level of $0 \mathrm{kPa}$ to $300 \mathrm{kPa}$, the changing speed for dry density is faster than later pressure level. Because in the former pressure level, it is most likely a procedure of grain breakage, which does not reflect the truly maximum density and optimum moisture content of the material. This is the specific feature of metamorphic phyllite compares to the normal soil and rock material. In the embankment filling study, this particular feature of phyllite should give priority position in case of the accuracy consideration. Otherwise without thinking it over, the construction quality and safety assurance may be affected greatly. After the pressure level of $400 \mathrm{kPa}$, the dry density does not show so great change and until the level of $600 \mathrm{kPa}$, it turns stable. Therefore, the 
maximum dry density is $2.46 \mathrm{~g} / \mathrm{cm}^{3}$ and correspond to $5.3 \%$ optimum moisture content at the pressure level of $600 \mathrm{kPa}$. So it is significant to choose the reliable pressure level for metamorphic phyllite while doing the study of embankment compaction analysis.

Table 1 Results of dry density and moisture content under different pressure level

\begin{tabular}{ccccccc}
\hline & \multicolumn{5}{c}{ moisture content w /\% } \\
\cline { 2 - 7 } $\begin{array}{c}\text { density } \rho / \\
\text { g/cm }\end{array}$ & 3 & 4 & 5 & 6 & 7 & 8 \\
\hline$\rho_{0}$ & 2.26 & 2.31 & 2.34 & 2.33 & 2.29 & 2.225 \\
$\rho_{100}$ & 2.28 & 2.335 & 2.36 & 2.35 & 2.32 & 2.245 \\
$\rho_{200}$ & 2.32 & 2.36 & 2.383 & 2.375 & 2.355 & 2.31 \\
$\rho_{300}$ & 2.35 & 2.38 & 2.404 & 2.405 & 2.38 & 2.34 \\
$\rho_{400}$ & 2.365 & 2.4 & 2.427 & 2.43 & 2.41 & 2.35 \\
$\rho_{500}$ & 2.374 & 2.417 & 2.439 & 2.44 & 2.41 & 2.352 \\
$\rho_{600}$ & 2.385 & 2.43 & 2.45 & 2.445 & 2.415 & 2.355 \\
\hline
\end{tabular}

California Bearing Ratio (CBR) Test. For the CBR test here, only sample under the pressure level of $600 \mathrm{kPa}$ is selected. Three density tests are conducted and each density utilizes three samples and the striking numbers are 30, 50, and 98, respectively. The results are shown in Fig. 3.

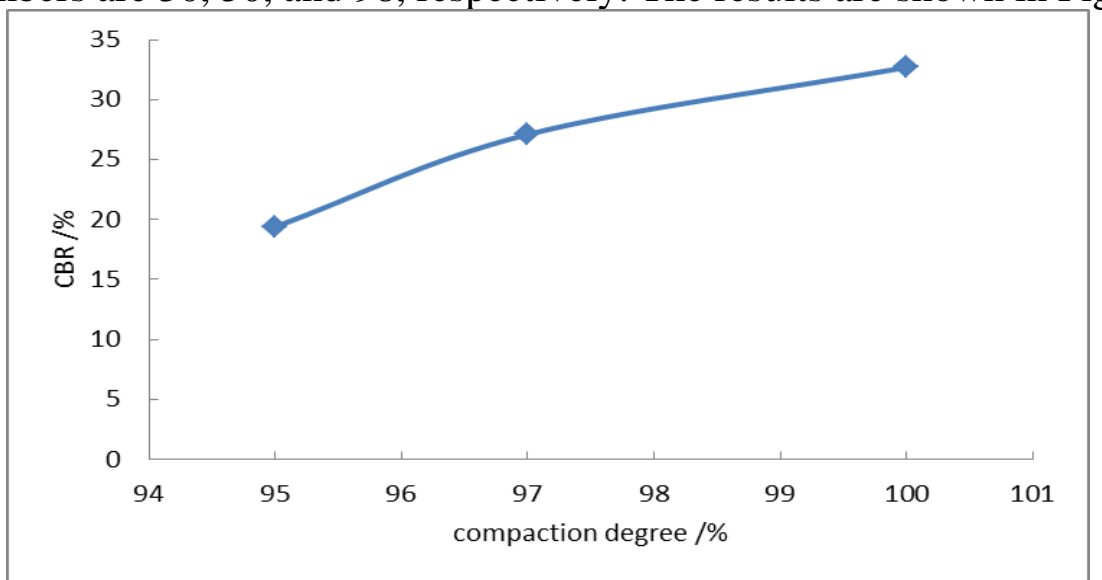

Figure 3 Relationship of compaction degree and CBR

The results indicate that the metamorphic phyllite CBR value meets the requirement of highway embankment filling criterion. Without doing extra improvement of the material of our abandoned material, it could meet our demand, but it still need pay attention to the reliable pressure level while using the metamorphic phyllite in the embankment construction. Not all types of metamorphic phyllite appears the same characteristics, before employing the material as the filler, specific grain size distribution and compaction test should do first to guarantee the accuracy and safety of the project.

\section{Summary}

For metamorphic phyllite in our project, the gradation shows great variation due to its fragile property. Based on this characteristic, the grain size distribution feature is studied according to different level of pressures. Through the tests, the pressure level of $600 \mathrm{kPa}$ seems to be the reliable state for compaction study.

Different pressure level samples are selected in the compaction test. During the 0 to $300 \mathrm{kPa}$ pressure, the dry density value change faster than 400-600 kPa. Among these seven pressure levels, the maximum dry density appears under the pressure of $600 \mathrm{kPa}$ and it is also to be treated as the reliable pressure level for compaction test according to the former study. The data of the tests also support this feature.

The CBR test results meet the requirement of the embankment filling criterion. For our project, the abandoned metamorphic phyllite could safely be used in the embankment filling in the view of 
compaction aspect. It is worth noting that not all types of metamorphic phyllite could be directly used without doing specific analysis.

\section{References}

[1] Yu Dehai, Peng Jianbing. Experimental study of mechanical properties of chlorite schist with water under triaxial compression[J]. Chinese Journal of Rock Mechanics and Engineering, 2009, 28(1): 205-211.

[2] Zhong Changyun, Wang Yonghe, Qing Qixiang. Research on compaction test analysis of the soft weathered rock[J]. Subgrade Engineering, 2007,134(5):83-85.

[3] Fang T., Diao X.H. 2007. Model test of settlement characters of soft rock subgrade [J]. Subgrade Engineering, 135(5): 83-85.

[4] Mao X.S., Zheng X.Z., Ma B. 2011. Field experimental analysis of wetting deformation of filled subgrade with weathered phyllite [J]. Rock and Soil Mechanics, 32(8):2300-2306.

[5] Xie Jinrong, Zhou Cuiying, Ma Biao. Method of seepage-softening analysis and disaster mechanism in soft rock slope under rainfall[J] . Rock and Soil Mechanics, 2011,32(8):2300-2306.

[6] Bo Gong-lin, Kojima Kobayashi. Design and construction of large scale sub-grade filling with soft rock and waste slag[J]. Soil and Foundation, 1984, 32(7): 53-59.

[7] Liu Jian, Li Jianpeng. Study of shear strength watersensitivity of intact schist from Gu-Zhu expressway[J]. Rock and Soil Mechanics, 2012, 33(6): 1719-1723.

[8] Liu Xinxi, Xia Yuanyou, Liu Zude, et al. Study of suitability for embankment of highly weathered soft rock subgrade[J]. Rock and Soil Mechanics, 2006, 27(6):903-907

[9] Zheng Mingxin, Fang Tao, Diao Xinhong, et al. Experimental study of feasibility of filled subgrade with weathered soft rock[J]. Rock and Soil Mechanics, 2005, 26(Supp.): 54-56. 